\title{
BAIL-IN DAN INTERCONNECTEDNESS: ISU HUKUM STRATEGIS DALAM PENCEGAHAN DAN PENANGANAN KRISIS SISTEM KEUANGAN $^{1}$
}

\author{
Lastuti Abubakar *, Tri Handayani \\ Departemen Hukum Ekonomi, Fakultas Hukum Universitas Padjadjaran \\ Jl. Raya Bandung Sumedang - Jatinangor \\ lastuti62abubakar@gmail.com
}

\begin{abstract}
Law No. $9 / 2016$ on the Prevention and Resolution of Financial System Crises regulated principles in the prevention and handling of finansial system crises that are not previously regulated. Therefore, this study will analyze the implementation of bail in principle and, interconnectedness in the prevention and resolution financial system crises. This research conducted by using normative juridical method with analytical descriptive approach and data is analyzed by juridical qualitative. Based on the research, the results show that the implementation of bail-in in handling of systemic bank done by optimized bank capability through capital surcharge The interconnectedness between the financial services sector requires a macro prudential policy complementary to micro prudential policy, and integrated supervision of the financial services sector.
\end{abstract}

Keywords: Bail in; Interconnectedness; Prevention and Handling of Financial System Crisis

\begin{abstract}
Abstrak
Undang-Undang No. 9 Tahun 2016 tentang Pencegahan dan Penanganan Krisis Sistem Keuangan mengatur prinsip-prinsip dalam pencegahan dan penanganan krisis sistem keuangan yang tidak diatur sebelumnya. Oleh karena itu, penelitian ini menganalisis implementasi prinsip bail in dan interconnectedness dalam pencegahan dan penanganan krisis sistem keuangan. Metode pendekatan yang digunakan adalah yuridis normatif dengan spesifikasi penelitian bersifat deskriptif analitis, dan data dianalisis secara yuridis kualitatif. Berdasarkan penelitian diperoleh hasil bahwa implementasi bail-in dalam penanganan bank sistemik dilakukan dengan mengoptimalkan kemampuan bank baik melalui penambahan modal (capital surcharge) maupun pengubahan utang atau investasi menjadi penyertaan (debt to equity swap). Saling keterkaitan (interconnectedness) antara sektor jasa keuangan menuntut adanya kebijakan makroprudensial yang bersifat melengkapi kebijakan mikroprudensial dan pengawasan sektor jasa keuangan yang terintegrasi.
\end{abstract}

Kata Kunci: Bail in; Interconnectedness; Pencegahan dan Penanganan Krisis Sistem Keuangan

\footnotetext{
1 Artikel ini merupakan bagian dari Riset Kompetensi Dosen Unpad (RKDU): Kesiapan Infrastruktur Hukum Perbankan Nasional Dalam Rangka Asean Banking Integration Framework (ABIF) Tahun 2017.
} 


\section{A. Pendahuluan}

Berlakunya Undang-Undang No. 9 Tahun 2016 tentang Pencegahan dan Penanganan Krisis Sistem Keuangan (UU PPKSK) tidak dapat dilepaskan dari kebutuhan akan adanya payung hukum yang mengatur upaya pencegahan dan penanganan krisis sistem keuangan. (Fransisca Ari Indrawati, 2017). Krisis keuangan Asia pada tahun 1997 membawa dampak yang sangat besar terhadap aktivitas ekonomi di beberapa negara Asia. Sebelum Juli 1997, banyak pihak meyakini bahwa kecil kemungkinan Indonesia akan terimbas krisis. Faktanya, sebulan setelah itu, ekonomi Indonesia terkena imbasnya. Gejolak diawali dengan merosotnya nilai tukar rupiah terhadap USD, yang mengakibatkan bank mulai mengalami kerugian, terutama bank yang mempunyai pinjaman dalam mata uang asing dan tidak melakukan lindung nilai (hedging) atas pinjamannya.

Gejolak kurs yang ditambah dengan pemburukan arus kas bank-bank menyebabkan bank menghadapi kesulitan likuiditas, yang mengakibatkan puluhan bank harus ditutup dengan konsekuensi perekonomian dapat lumpuh total. Oleh karena itu upaya penyelamatan bank merupakan pilihan yang diambil dengan konsekuensi biaya yang harus dikeluarkan tidak sedikit mengingat banyaknya bank yang harus diselamatkan (Bank Indonesia, 2010).

Pada tahun 2008, krisis ekonomi kembali melanda dunia akibat kehancuran bisnis properti di Amerika Serikat akibat macetnya kredit properti melalui kredit nonbank (sub-prime mortgage). Kredit dengan syarat ringan; debitor yang tidak memiliki kredit terbaik (sub-prime lending) dengan bunga tinggi; pengetatan kebijakan pemberian pinjaman akibat penurunan pasar sub-prime mortgage menjadi penyebab sulitnya mendapatkan pinjaman untuk bertahan hidup, yang akhirnya menyebabkan kredit macet (Moran, Johal, \& Williams, 2011). Akibatnya banyak institusi keuangan mengalami kesulitan.
Lehman Brothers, salah satu institusi keuangan besar yang bertindak selaku agen atau perantara antara para investor dan calon debitor sub-prime mortgage menyatakan diri bangkrut setelah gagal mendapatkan opsi Chapter 11 Protection, yaitu mekanisme emergensi terhadap lembaga keuangan di AS yang mengalami masalah likuiditas untuk meminta pertolongan otoritas moneter (Bank Indonesia, 2010). Krisis di AS ini memicu terjadinya krisis ekonomi dan keuangan global, yang imbasnya dirasakan kembali oleh negara-negara di dunia termasuk Indonesia. Dampaknya perusahaan-perusahaan nasional yang mengandalkan bahan baku impor dan para pemilik modal harus menanggung beban akibat melemahnya nilai tukar. Saat itu, transaksi lindung nilai (hedging) sebagai upaya antisipasi untuk memproteksi nilai mata uang belum populer di kalangan perusahaan nasional, walaupun ada perusahaan yang menggunakan hedging sebagai upaya mitigasi risiko fluktuasi nilai tukar. Mengingat pentingnya transaksi hedging ini, Bank Indonesia kembali menerbitkan serangkaian kebijakan tentang transaksi valuta asing terhadap rupiah baik antara Bank dengan Pihak Asing maupun antara Bank dengan Pihak Domestik untuk mendorong pelaku usaha agar menggunakan transaksi lindung nilai sebagai upaya untuk mengantisipasi kerugian akibat perubahan nilai tukar (Bank Indonesia, 2010).

Krisis ekonomi dan keuangan global ini pun kembali menimbulkan kepanikan di pasar keuangan global termasuk perbankan. Perbankan Indonesia yang saat krisis tidak lagi memberlakukan penjaminan dana nasabah secara penuh (blanket guarantee) menderita capital outflow yang lebih parah dibandingkan dengan negara tetangga yang memberlakukan penjaminan dana nasabah secara penuh. Kondisi ini menyebabkan bank-bank mengalami kesulitan likuiditas sehingga memaksa bank-bank besar seperti PT Bank Mandiri Tbk, PT Bank BNI Tbk, dan PT BRI Tbk meminta bantuan likuiditas kepada Pemerintah yang digunakan untuk memperkuat cadangan modal atau 
memenuhi komitmen kredit infrastruktur tanpa harus terganggu likuiditasnya (Bank Indonesia, 2010).

Langkah yang diambil oleh Pemerintah dan Bank Indonesia selaku otoritas perbankan untuk mengantisipasi krisis adalah dengan menerbitkan regulasi dan menyempurnakan kebijakan. Pemerintah telah menerbitkan Peraturan Pemerintah Pengganti Undang-Undang (PERPU) No. 2 Tahun 2008 tentang Perubahan Kedua atas Undang-Undang No. 23 Tahun 1999 tentang Bank Indonesia yang memungkinkan kredit berkolektabilitas lancar dijadikan agunan guna mendapatkan Fasilitas Pendanaan Jangka Pendek (FPJP). Kedua, PERPU No. 3 Tahun 2008 tentang Perubahan UU No. 24 Tahun 2004 tentang LPS, yang digunakan sebagai dasar hukum untuk menaikkan nilai simpanan nasabah yang dijamin dari $\mathrm{Rp}$. 100 juta menjadi Rp. 2 miliar. Ketiga, PERPU No. 4 Tahun 2008 Tentang Jaring Pengaman Sistem Keuangan (JPSK), yang merupakan kerangka kerja melandasi pengaturan mengenai skim asuransi simpanan, mekanisme pemberian fasilitas pembiayaan darurat oleh bank sentral (lender of the last resort) serta kebijakan penyelesaian krisis.

Jaring Pengaman Sistem Keuangan ini pada dasarnya lebih ditujukan untuk pencegahan krisis, namun demikian kerangka kerja ini juga meliputi mekanisme penyelesaian krisis agar tidak menimbulkan biaya yang besar kepada perekonomian. Sasaran JPSK adalah menjaga stabilitas sistem keuangan sehingga sektor keuangan dapat berfungsi secara normal dan memiliki kontribusi positif terhadap pembangunan ekonomi yang berkesinambungan (Bank Indonesia, n.d.) Dalam perkembangannya, RUU JPSK yang diajukan oleh Pemerintah ini mengalami perubahan dengan terbitnya UU PPKSK.

Belajar dari penanganan Bank Century yang dinyatakan berdampak sistemik dan mengharuskan pemerintah melakukan penyelamatan melalui bail out, yaitu suatu tindakan bisnis yang menyediakan uang dan sumber daya (yang juga dikenal sebagai suntikan modal) kepada bank yang dinyatakan gagal (Twin, 2019) telah memberikan pengalaman berharga bagi Indonesia dalam melakukan pencegahan dan penanganan krisis sistem keuangan. Salah satu isu hukum yang mengemuka dalam penanganan Bank Century adalah perdebatan mengenai kriteria bank sistemik, sehingga perlu di-bail out, mengingat tidak ada regulasi yang dapat dijadikan landasan hukum untuk menentukan kriteria bank gagal dapat dinyatakan sistemik atau tidak berdampak sistemik. Kriteria Bank Sistemik ini menjadi salah satu substansi pengaturan dalam UU PPKSK yang memberikan definisi tentang bank sistemik. Pasal 1 Angka 5 UU PPKSK mendefinisikan Bank Sistemik adalah :

"Bank yang karena ukuran aset, modal, dan kewajiban; luas jaringan atau kompleksitas transaksi atas jasa perbankan; serta keterkaitan dengan sektor keuangan lain dapat mengakibatkan gagalnya sebagian atau seluruh Bank lain atau sektor jasa keuangan, baik secara operasional maupun finansial, jika Bank tersebut mengalami gangguan atau gagal".

Selanjutnya, indikator untuk menetapkan Bank Sistemik diatur dalam Pasal 5 POJK No. 2/POJK.03/2018 tentang Penetapan Bank Sistemik dan Capital Surcharge, yaitu: ukuran Bank (size); kompleksitas kegiatan usaha (complexity); dan keterkaitan dengan sistem keuangan (interconnectedness). Selain itu, UU PPKSK menggunakan pendekatan baru dalam penanganan krisis sistem keuangan, yaitu dengan mengutamakan penggunaan sumber daya bank itu sendiri dan pendekatan bisnis tanpa menggunakan anggaran negara (bail in). Perubahan pendekatan dalam UU PPKSK yaitu bail-in dan keterkaitan dengan sistem keuangan (interconnectedness) ini menimbulkan implikasi hukum terhadap metode dan mekanisme pencegahan dan penanganan krisis sistem keuangan. 
Selain mewajibkan perbankan untuk memperkuat permodalan, penerapan prinsip bail-in akan mendorong bank untuk lebih mengedepankan prudential banking principle dalam setiap aktivitasnya sebagai upaya pencegahan kegagalan bank. Berdasarkan latar belakang yang telah diuraikan, maka dapat diidentifikasi permasalahan sebagai berikut: 1) Bagaimanakah implementasi bail in dalam pencegahan dan penanganan krisis sistem keuangan, khususnya dalam penanganan bank sistemik?; 2) Bagaimanakah implikasi yuridis keterkaitan sistem keuangan (interconnectedness) terhadap kebijakan pencegahan dan penanganan krisis sistem keuangan?

Untuk mendukung penelitian ini, sebelumnya telah dilakukan penelitian tentang: 1) Kesiapan Infrastruktur Perbankan Dalam Rangka Menghadapi Asean Banking Integration Framework (ABIF); 2) Transaksi Lindung Nilai (Hedging) Dalam Praktik Perbankan dan Implikasinya Terhadap Pembaruan Hukum Kontrak Nasional; dan 3) Regulasi Pengelolaan Likuiditas Bank melalui Kewajiban Penerapan Net Stable Funding Ratio (NSFR) Sebagai Upaya Menciptakan Perbankan yang Sehat. Penelitian ini menganalisis perubahan dan perkembangan prinsip dalam UU PPKSK dalam pencegahan dan penanggulangan krisis keuangan sebagai upaya untuk menciptakan perbankan yang sehat dan berdaya saing.

\section{B. Metode Penelitian}

Sesuai dengan bidang kajian ilmu hukum, pendekatan yang dipakai dalam penelitian ini adalah yuridis normatif, yang lebih menitikberatkan pada studi kepustakaan untuk mengkaji implementasi prinsip bail-in dan keterkaitan dengan sistem keuangan (interconnectedness) dalam pencegahan dan penanganan krisis sistem keuangan. Penelitian ini didukung pula oleh metode sejarah hukum, perbandingan hukum dan penafsiran hukum.

Penelitian ini bersifat deskriptif analitis yaitu menggambarkan dan menganalisis data yang diperoleh berupa data sekunder yang terdiri dari bahan hukum primer, sekunder dan tersier mengenai permasalahan yang berkaitan dengan prinsip bail-in dan keterkaitan dengan sistem keuangan (interconnectedness) dalam pencegahan dan penanganan krisis sistem keuangan. Analisis data yang digunakan di dalam penelitian ini adalah analisis data yuridis kualitatif dengan menggunakan daya abstraksi dan penafsiran hukum (interpretasi), untuk selanjutnya dituangkan dalam bentuk uraian-uraian (deskripsi).

\section{Hasil dan Pembahasan}

\section{Implementasi Bail In dalam Pencegahan dan Penanganan Krisis Sistem Keuangan, Khususnya dalam Penanganan Bank Sistemik}

Pengalaman krisis dan penanganan bank gagal di masa lalu menyadarkan pemerintah dan otoritas keuangan akan pentingnya payung hukum yang kokoh; koordinasi yang kuat antar otoritas sistem keuangan yang selama ini menangani permasalahan berdasarkan kewenangan masing-masing; serta perlunya penerapan best practices dalam pencegahan dan penanganan permasalahan stabilitas sistem keuangan.

Perkembangan sistem keuangan nasional yang dipengaruhi oleh tatanan dan regulasi sistem keuangan global turut mempengaruhi perubahan kebijakan dan regulasi dalam pencegahan dan penanganan krisis di Indonesia. Krisis keuangan global mendorong pemimpin negara-negara G-20 pada pertemuan di Seoul tahun 2010 meminta kepada Financial Stability Board (FSB), International Monetary Fund (IMF), dan Bank for International Settlement (BIS) untuk mengembangkan kerangka kebijakan makroprudensial guna mencegah risiko sistemik pada sektor keuangan. Sebagai tindak lanjut, bank sentral dan otoritas keuangan beberapa negara turut mengembangkan pendekatan makroprudensial dalam menjaga stabilitas sistem keuangan, antara lain melalui tren perubahan penataan kelembagaan 
(institutional arrangement) keuangan di beberapa negara (Bank Indonesia, 2016). Dengan demikian, dapat dimengerti mengapa kebijakan makroprudensial menjadi salah satu isu hukum yang penting dalam UU PPKSK.

Kebijakan makroprudensial menjadi relevan dalam pencegahan dan penanganan krisis sistem keuangan, mengingat sistem keuangan tidak cukup apabila hanya difokuskan pada tingkat kesehatan dan kinerja individu bank atau institusi keuangan lainnya. Hal ini sejalan dengan perkembangan pendekatan berdasarkan sifat keterkaitan (interconectedness), yang mengakibatkan kegagalan pada satu bank dapat berdampak pada bank lain atau bahkan beberapa bank sekaligus yang memiliki transaksi keuangan dengan bank tersebut. Risiko inilah yang dalam Peraturan Bank Indonesia No. 16/11/2014 tentang Pengaturan dan Pengawasan Makroprudensial lazim disebut risiko sistemik, yaitu "Potensi instabilitas sebagai akibat terjadinya gangguan yang menular (contagion) pada sebagian atau seluruh Sistem Keuangan karena interaksi dari faktor ukuran (size), kompleksitas usaha (complexity), dan keterkaitan antar institusi dan/atau pasar keuangan (interconnectedness), serta kecenderungan perilaku yang berlebihan dari pelaku atau institusi keuangan untuk mengikuti siklus perekonomian (procyclicality)"

Berdasarkan penafsiran sistematis, dapat disimpulkan bahwa UU PPKSK menggunakan keterkaitan dengan sektor keuangan (interconnectedness) sebagai pendekatan yang digunakan dalam mekanisme penanganan dan pencegahan krisis sistem keuangan. Pengaturan dalam UU PPKSK berfokus pada bank, dan tidak menyinggung tentang lembaga keuangan nonbank, namun menekankan pada pencegahan dan penanganan Bank Sistemik, yang salah satu indikatornya adalah keterkaitan dengan sektor keuangan (interconnectedness).

Selain pendekatan bail in dan interconnectedness, Pasal 2 UU PPKSK meletakkan asas-asas dalam pencegahan dan penanganan krisis sistem keuangan yaitu asas kepentingan nasional; kemanfaatan; keadilan; keterpaduan; efektivitas; efisiensi; dan kepastian hukum. Berdasarkan prinsip dan asas-asas tersebut, pencegahan dan penanganan krisis sistem keuangan diharapkan dapat dilakukan secara tepat berdasarkan kerja sama yang baik, terkoordinasi dan saling mendukung, yang pada akhirnya dapat bermanfaat bagi kepentingan bangsa, negara dan mewujudkan cita-cita kesejahteraan umum serta mengutamakan kepentingan bangsa, negara, dan masyarakat di atas kepentingan lainnya.

Dalam UU PPKSK, penanganan permasalahan bank sistemik diutamakan menggunakan sumber daya bank itu sendiri (bail in) dan pendekatan bisnis tanpa menggunakan anggaran negara. Jika upaya penanganan ini belum dapat mengatasi permasalahan, penanganan dilakukan dengan dukungan Bank Indonesia untuk penanganan masalah likuiditas dan LPS untuk penanganan masalah solvabilitas. Bail-in merupakan strategi penyelesaian yang diadopsi dari kesepakatan anggota International Association Deposits Insurers (IADI), yang mendefinisikan bail in sebagai:

" a mechanism to recapitalise a bank
inresolution or effectively capitalise a
bridge bank, under specified conditions,
through the write-down, conversion or
exchange of debt instrument and other
senior or subordinated unsecured
liabilities of the bank in resolution
into/for equity or other instruments in
that bank, the parent company of the
bank or newly formed bridge bank, as
appropriate to the legal framework and
market capacity" (IADI, 2014).

Prinsip ini selanjutnya di elaborasi dalam POJK No. 14/POJK.03/2017 tentang Rencana Aksi (Recovery Plan) Bagi Bank Sistemik (POJK Recovery Plan), yaitu rencana untuk mengatasi permasalahan keuangan (solvabilitas dan likuiditas) yang 
mungkin terjadi di Bank Sistemik. Pasal 23 POJK Recovery Plan mengatur tentang implementasi bail in yang dapat berupa: 1) Penambahan modal Bank Sistemik (capital surcharge) dan mengubah jenis utang atau investasi tertentu menjadi modal Bank Sistemik, yang menjadi kewajiban Pemegang Saham pengendali (PSP) dan/atau ultimate shareholders, dan/atau 2) Penambahan modal Bank Sistemik dan mengubah jenis uang atau investasi tertentu menjadi modal Bank Sistemik yang mengikutsertakan pihak lain.

Penguatan kondisi keuangan bank sistemik dengan mewajibkan penambahan modal (capital surcharge) berfungsi untuk mengurangi dampak negatif terhadap stabilitas sistem keuangan dan perekonomian dalam hal terjadi kegagalan Bank Sistemik melalui peningkatan kemampuan Bank dalam menyerap kerugian. Strategi resolusi bank sistemik melalui penambahan modal ini dikenal sebagai open bank bail-in atau rekapitalisasi entitas dalam penyelesaian (a recapitalisation of the entity in resolution) (Financial Stability Board, 2018b).

Dalam penetapan opsi pemulihan, Bank Sistemik dapat melakukan Pinjaman Likuiditas Jangka Pendek (PLJP) atau Pembiayaan Likuiditas Jangka Pendek berdasarkan prinsip syariah kepada Bank Indonesia sebagai instrumen dalam penanganan likuiditas bank. Hal ini sejalan dengan fungsi Bank Indonesia sebagai lender of the last resort (Zaini, 2013).

Strategi bail in lainnya adalah closed bank bail in, yaitu penyelesaian bank sistemik yang mengalami permasalahan solvabilitas. Metode ini diadaptasi dalam Peraturan LPS No. 1 Tahun 2017 tentang Penanganan Bank Sistemik yang Mengalami Permasalahan Solvabilitas. Pasal 6 PLPS tersebut mengatur bahwa LPS melakukan penanganan bank sistemik melalui beberapa cara, yaitu: 1) Purchase And Assumption (P\&A), yaitu pengalihan sebagian atau seluruh aset dan/atau kewajiban bank kepada Bank Penerima. Dalam hal nilai kewajiban yang dialihkan lebih besar dibandingkan aset yang dialihkan, maka selisihnya ditutup secara cash oleh LPS; 2) Bridge Bank, yaitu Bank umum yang didirikan oleh LPS yang digunakan sebagai sarana resolusi dengan menerima pengalihan sebagian atau seluruh aset dan/atau kewajiban Bank yang ditangani LPS. Apabila nilai kewajiban yang dialihkan lebih besar dibandingkan aset yang dialihkan, maka selisihnya ditutup secara cash oleh LPS; dan 3) Sesuai dengan UU LPS, yaitu cara penanganan bank sistemik yang dilakukan dengan penambahan modal oleh LPS ke dalam bank dengan atau tanpa mengikutsertakan pemegang saham lama.

Implementasi bail in yang memerlukan kajian lebih lanjut adalah berkenaan dengan pengubahan utang atau investasi menjadi penyertaan (debt to equity swap). Penulis berpendapat bahwa opsi ini perlu diatur secara seksama karena akan berimplikasi terhadap kedudukan dan tanggung jawab pihak yang berpiutang menjadi pemilik, yang akibat hukumnya akan menimbulkan tanggung jawab yang berbeda. Mengingat opsi ini diatur dalam peraturan perundangundangan, sedangkan hubungan hukum antara Bank dengan pemilik dana atau investor berlandaskan pada perjanjian, maka isu hukum yang muncul adalah apakah perjanjian dapat diubah tanpa kesepakatan, namun cukup merujuk pada ketentuan perundang-undangan yang bersifat voluntary rules.

Namun demikian, bail-in merupakan mekanisme yang tepat, karena disamping tidak membebani APBN, secara tidak langsung akan mendorong perbankan untuk memperkuat permodalan. Penguatan struktur permodalan ini selanjutnya dituangkan dalam POJK No. 50/POJK.03/2017 tentang Kewajiban Pemenuhan Rasio Pendanaan Stabil Bersih (Net Stable Funding Ratio/NSFR) yang bertujuan mengurangi risiko likuiditas terkait sumber pendanaan untuk jagka waktu yang lebih panjang dengan sumber pendana mensyaratkan bank untuk mendanai aktivitas dengan sumber dana stabil yang memadai dalam rangka memitigasi risiko kesulitan pendanaan pada 
masa depan. Melalui kewajiban pemenuhan NFSR, Bank diharapkan mampu mencapai tingkat kesehatan Bank agar dapat bersaing baik di tingkat nasional maupun internasional (Handayani \& Abubakar, 2018).

Lebih lanjut, perbankan akan terpacu untuk lebih inovatif dalam melakukan pengembangan produk dan layanan untuk meningkatkan aset dan permodalan. Perubahan perilaku perbankan ini akan mempercepat perbankan nasional untuk memenuhi persyaratan memenuhi Qualified Asean Banks (QABs) untuk menyongsong Asean Banking Integration Framework (ABIF) pada tahun 2020 (Handayani \& Abubakar, 2016).

\section{Implikasi Yuridis Penggunaan Pendekatan Interconnectedness terhadap Urgensi Kebijakan Makroprudensial dalam Pencegahan dan Penanganan Krisis Sistem Keuangan}

International Monetary Fund (IMF) mengakui bahwa sejak pertengahan 1990, negara-negara secara keuangan semakin saling terkait (financial interconnectedness). IMF memberikan pengertian interconnectedness sebagai berikut:

"Countries are financially
interconnectedness through the asset
and liability management (ALM)
strategies of their sovereigns, financial
institutions, and corporations. This
financial globalization has borught
benefits as well ass vulnerabilities. In
particular, the speed with which
illiquidity and losses in some markets
can translate into global asset
recomposition points to the risks of
interconnectedness" (IMF, 2010:5).

Mengacu pada pengertian di atas, dapat ditafsirkan bahwa negara-negara secara keuangan saling terkait melalui strategi pengelolaan aset dan kewajiban dari otoritas, lembaga keuangan dan korporasi. Dalam tataran global, interconectedness ini pun menjadi ukuran untuk mengklasifikasikan lembaga keuangan yang termasuk ke dalam Global Systematically Important Banks (GSIBs) yaitu Bank-bank yang sistemik secara global. Pada tahun 2018 Financial Stability Board (FSB) telah mengeluarkan daftar GSIBs menggunakan data 2017 akhir dan metodologi asesmen yangdi desain oleh the Basel Committee on Banking Supervision $(B C B S)$ yang diklasifikasikan ke dalam 4 kategori berdasarkan sistem bucket, yaitu metodologi yang digunakan oleh Basel Commite on Banking Supervisory (BSBS). Satu bank (Group BPCE) telah ditambahkan ke dalam daftar dan 2 bank (Nordea dan Royal Bank of Scotland) telah dikeluarkan dari daftar, sehingga jumlah bank yang masuk dalam daftar G-SIBs adalah 29 Bank (Financial Stability Board, 2018a).

Berdasarkan Pasal 17 UU PPKSK, OJK berkoordinasi dengan Bank Indonesia menetapkan Bank Sistemik., dan penetapan pertama kali dilakukan pada kondisi stabilitas sistem keuangan normal. Selanjutnya, pemutakhiran data dilakukan secara berkala 1 kali dalam 6 bulan.

Implikasi yuridis dari saling keterkaitan sektor keuangan (financial interconnectedness) sebagai paradigma baru dalam penanganan krisis sistem keuangan ini, sebelumnya sudah dielaborasi ke dalam pasal-pasal dalam Undang-undang No. 21 Tahun 2011 tentang Otoritas Jasa Keuangan (UU OJK). Pasal 5 UU OJK mengatur "OJK berfungsi menyelenggarakan sistem pengaturan dan pengawasan yang terintegrasi terhadap keseluruhan kegiatan di dalam sektor jasa keuangan".

Pengawasan terintegrasi ini tidak dapat dilepaskan dari latar belakang dibentuknya UU OJK, yaitu proses globalisasi dalam sistem keuangan dan pesatnya teknologi informasi serta inovasi finansial yang telah menciptakan sistem keuangan yang kompleks, dinamis, dan saling terkait antar subsektor keuangan baik dalam hal produk maupun kelembagaan. Tampak bahwa isu saling keterkaitan (interconnectedeness) yang berpotensi menyebabkan suatu bank menjadi sistemik tidak dapat dihindari. Oleh 
karena itu, pengawasan terintegrasi merupakan salah satu upaya untuk melakukan pencegahan krisis sistem keuangan secara dini.

Selain pengawasan terintegrasi pada seluruh sektor jasa keuangan, keterkaitan dengan sektor keuangan (interconnectedness) dalam penanganan krisis sistem keuangan, menuntut adanya koordinasi antara OJK dan BI, mengingat penanganan krisis keuangan berkaitan erat dengan kebijakan makroprudensial yang mandat pengawasan dan pengaturannya merupakan kewenangan Bank Indonesia. Penjelasan Pasal 7 UU OJK menjelaskan bahwa lingkup pengaturan dan pengawasan makroprudensial merupakan tugas dan wewenang Bank Indonesia. Hal ini ditegaskan kembali dalam Pasal 3 Ayat (2c) UU PPKSK, yang menekankan adanya koordinasi pemantauan dan pemeliharaan Stabilitas Sistem Keuangan (SSK), antara lain mencakup bidang makroprudensial dan mikroprudensial. Baik UU OJK maupun UU PPKSK tidak mendefinisikan apa yang dimaksud dengan kebijakan makroprudensial. Penjelasan Pasal 3 Ayat (2c) menjelaskan bahwa makroprudensial mencakup pengaturan dan pengawasan lembaga jasa keuangan yang bersifat makro dan berfokus pada risiko sistemik dalam rangka mendorong Stabilitas Sistem Keuangan.

Sebagai acuan dan perbandingan, IMF mendefinisikan makroprudensial secara luas sebagai "macroprudential policy is seen as a policy aimed at maintaining financial stability" dan secara sempit sebagai "prundential tools set up with a macro (system-wide) lens (International Monetary Fund, 2011). Definisi tersebut dapat dimaknai sebagai kebijakan yang memiliki tujuan untuk memelihara stabilitas sistem keuangan, yang difokuskan pada penerapan prinsip kehati-hatian secara keseluruhan.

Merujuk pada beberapa definisi di atas, kata kunci untuk menggambarkan kebijakan makroprudensial sebagai kebijakan yang bertujuan menjaga stabilitas keuangan, dengan berorientasi pada sistem keuangan secara keseluruhan (system-wide perpectives) melalui upaya terbangunnya (build-up) risiko sistemik. Dengan kata lain, kebijakan makroprudensial merupakan penerapan prinsip kehati-hatian (prudential principle) pada sistem keuangan guna menjaga keseimbangan antara tujuan makroekonomi dan mikroekonomi (Bank Indonesia, 2016).

Berdasarkan uraian di atas, penanganan krisis sistem keuangan menempatkan kebijakan makroprudensial sebagai bagian dalam pencegahan dan penanganan krisis sistem keuangan. Peran Bank Indonesia selaku pemegang mandat pengaturan dan pengawasan makroprudensial dapat dibedakan ke dalam 2 fungsi yaitu upaya pencegahan krisis sistem keuangan dan upaya penanganan krisis sistem keuangan.

Berdasarkan Pasal 16, 17, 20 dan 30 UU PPKSK upaya pencegahan meliputi: pemantauan dan pemeliharaan stabilitas sistem keuangan, koordinasi penetapan Bank Sistemik dan pemberian Pinjaman Likuiditas Jangka Pendek (PLJP) atau pembiayaan likuiditas jangka pendek berdasarkan prinsip syariah. Sedangkan peran BI dalam rangka penanganan krisis sistem keuangan diatur dalam dalam Pasal 37 yang mengatur tentang PLJP dalam kondisi krisis sistem keuangan, pembelian SBN milik LPS dalam kondisi krisis sistem keuangan serta dukungan terhadap Program Restrukturisasi Perbankan (PRP) yang pelaksanaannya dilakukan oleh LPS. Selain fungsi BI yang diatur dalam UU PPKSK, tentu fungsi BI mengacu pada UndangUndang No. 23 Tahun 1999 tentang Bank Indonesia, yang telah diubah terakhir kalinya dengan UU No. 2 Tahun 2008. Dengan demikian, Fungsi BI sebagai otoritas moneter berdasarkan UU BI dan BI sebagai pemegang mandat pengaturan dan pengawasan makroprudensial sangat relevan dalam menciptakan stabilias sistem keuangan.

\section{Simpulan dan Saran}

Undang-Undang PPKSK menggunakan pendekatan bail-in dan meniadakan 
penggunaan APBN dalam penanganan krisis sistem keuangan, khususnya penanganan bank sistemik. Implementasi prinsip ini berupa open bank bail in yaitu penambahan modal (capital surcharge) atau pengubahan utang atau investasi penjadi penyertaan (debt to equity swap); dan closed bank bail in yaitu pengalihan sebagian atau seluruh aset dan kewajiban bank (Purchase and Assumption) kepada Bank Penerima atau Bridge Bank (Bank Perantara), atau penyertaan modal sementara sesuai dengan UU LPS.

Isu strategis lainnya adalah keterkaitan dengan sektor keuangan (interconnectedness) yang berpotensi menimbulkan risiko sistemik. Keterkaitan dengan sektor keuangan (interconnectedness) berimplikasi terhadap urgensi kebijakan makroprudensial dalam pencegahan dan penanganan krisis sistem keuangan. Bank Indonesia selaku pemegang mandat pengaturan dan pengawasan makroprudensial berperan dalam melakukan pencegahan dan penanganan krisis sistem keuangan. Dalam upaya pencegahan, BI melakukan pemantauan dan pemeliharaan stabilitas sistem keuangan serta menjalankan fungsi lender of the last resort.

Berkaitan dengan strategi bail in ini, saran yang harus dapat penulis ajukan adalah perlunya pengaturan yang secara cermat dapat menerjemahkan mekanisme debt to equity swap. Selain itu, untuk mengotimalkan koordinasi antara OJK selaku ototitas mikroprudensial dan BI selaku otoritas moneter dan makroprudensial, maka kerjasama dan koordinasi antara OJK dan BI, serta antar anggota KKSK perlu diterjemahkan ke dalam Standard Operating Procedure (SOP) yang jelas dan rinci sebagai pedoman bagi setiap anggota KKSK dalam menjalankan fungsi dan perannya.

\section{DAFTAR PUSTAKA}

Bank Indonesia. (n.d.). Stabilitas Sistem Keuangan - Bank Sentral Republik
Indonesia. Retrieved from https://www.bi.go.id/id/perbankan/Cont ent/default.aspx

Bank Indonesia. (2010). Bank Indonesia. Retrieved from http://www.bi.go.id/web/id/Ruang+Med ia/Berita/buku_krisis_global_180110_b erita.htm

Bank Indonesia. (2016). Mengupas Kebijakan Makroprudensial. Jakarta.

Financial Stability Board. (2018a). 2016 List of Global Systemically Important Banks.

Financial Stability Board. (2018b). Principles on Bail-in Execution. Retrieved from http://www.fsb.org/wpcontent/uploads/P210618-1.pdf

Fransisca Ari Indrawati. (2017). ISSN : 1693 - $3265 . \quad$ Buletin Hukum Kebanksentralan, 14(2), 1-42.

Handayani, T., \& Abubakar, L. (2016). Implikasi KEsepakatan ASEAN Banking INtegration (ABIF)Terhadap Pembaruan Hukum Perbankan Indonesia. Rechtidee, 11(2), 136-149.

Handayani, T., \& Abubakar, L. (2018). Regulasi Pengelolaan Likuiditas Bank melalui Kewajiban Penerapan Net Stable Funding Ratio ( NSFR ) sebagai Upaya Menciptakan Perbankan yang Sehat. Varia Justica.

IADI. (2014). Core Principles for Effective Deposit Insurance Systems International Association of Deposit Insurers. International Association of Deposit Insured, (November), 1-7.

International Monetary Fund. (2011). Macroprudential Policy: An Organizing Framework. In Monetary and Capital MArket.

Moran, M., Johal, S., \& Williams, K. (2011). The financial crisis and its consequences. Britain at the Polls 2010, (December), 89-119. https://doi.org/10.4135/9781446269220. $\mathrm{n} 4$ 
Twin, A. (2019). What Is A Bailout?

Zaini, Z. D. (2013). Sentral Dengan Otoritas Jasa Keuangan (OJK) Pasca. Jurnal Media Hukum, 20(2), 365-383. 